\title{
Effects of Temperature and Precipitation on Spatiotemporal Variations of Net Primary Productivity in the Qinling Mountains, China
}

\author{
Tao Wang *, Meihuan Yang1, Suijun Yan²,Guangpo Geng¹, Qihu Li', Feng Wang³ \\ ${ }^{1}$ College of Geomatics, Xi' an University of Science and Technology, 58 Yanta Road, Xi'an, China \\ ${ }^{2}$ Shandong Branch of China National Geological Exploration Center of Building Materials Industry, \\ 32 Shanda North Road, Jinan, China \\ ${ }^{3}$ Ocean Wood Mapping Information Technology Limited Company, 69 South Second Ring Road, Xi'an, China
}

Received: 24 December 2019

Accepted: 25 May 2020

\begin{abstract}
The Qinling Mountains are an important geographic boundary in central and eastern China. The region has diverse and complex mountain ecosystems that are ideal to study the response of terrestrial ecosystems in the context of global climate change. Based on GIMMS NDVI data, meteorological data, and DEM and vegetation type data, we used the Comprehensive and CASA (Carnegie Ames Stanford Approach) models simulate NPP (Net Primary Productivity) and the response to climate change in the Qinling Mountains from 1982 to 2015. The research includes three main aspects: (1) MOD17A3 NPP data was used to compare the accuracy of the NPP values obtained by different methods. The NPP values calculated using the CASA model and GIMMS NDVI were most accurate without considering the vegetation type. (2) Changes in NPP were analyzed. The change trend of inter-annual and seasonal NPP was not significant temporally, but the inter-annual and spring NPP increased significantly, reaching $35.49 \%$ and $57.84 \%$ of the total study area, respectively, while the area of winter NPP significantly reduced by $22.87 \%$. (3) The relationship between NPP and air temperature and precipitation was analyzed. The proportion of significant positively correlated inter-annual and spring NPP and precipitation values were higher, reaching $31.20 \%$ and $21.20 \%$, respectively, while the proportion of significant positively correlated spring and autumn NPP values were only $10.80 \%$ and $10.20 \%$, respectively. The complexity of the Qinling mountainous system enhances the heterogeneity of spatial and temporal variations in NPP and the response to climate change.
\end{abstract}

Keywords: comprehensive model, CASA model, spatio-temporal variation, correlation analysis, Qinling Mountains

*e-mail: wht432@xust.edu.cn 


\section{Introduction}

Research on the impacts of global climate change is a current area of focus for scholars in different fields [1-2]. Terrestrial vegetation is an important part of the global ecosystem, and is closely related to biodiversity. Terrestrial vegetation in ecosystems experiences severe changes due to global warming [3]. The five consecutive assessment reports from the Intergovernmental Panel on Climate Change (IPCC) (1990, 1995, 2001, 2007 and 2013) have all shown that global warming is unquestionably occurring, and that regions at high latitudes and high altitudes have been the most sensitive to that change [4]. As an important geographical boundary between central and eastern China, the Qinling Mountains have diversely vegetated and complex ecosystems, and are an ideal place to study the response of terrestrial vegetation to climatic changes.

Although there are still many uncertainties in projections of global warming [5], the UN-FCCC has recommended actions to reduce and mitigate the impacts by limiting and reducing $\mathrm{CO}_{2}$ emissions, but these actions are voluntary, and the majority of countries have not met their voluntary country commitments. Most efforts to accomplish this have been made through reductions in fossil fuel consumption or increases in intensive use efficiency. In the global carbon emissions reduction process, vegetated terrestrial ecosystems have the added function of carbon fixation and oxygen release [6], and the temporal and spatial patterns of vegetation net primary productivity (NPP) and their response to climate change have received extensive attention [7-10]. Considering these trends, investigating and quantifying the temporal and spatial variation of NPP response to climate change in the Qinling Mountains has the dual theoretical significance of reflecting both global and regional climate change impacts and guiding regional strategies for carbon emission reduction.

NPP is mainly controlled by climatic factors and has certain sensitivities to and lags changes in climate. The response of NPP to climate change has become an indicator of the direction of regional ecological change, and research has focused on two aspects: stable and extreme climates. With respect to stable climates, Nemani et al. argued that global climate change in 1982-1999 reduced the level of key factors limiting plant growth, resulting in a $6 \%$ increase in global NPP [11]. Zhao et al. showed that the reduction of heat and water stress on plant growth did not increase vegetation NPP from 2000 to 2010, but that a global drought event reduced NPP levels [12-13]. Zhu et al. showed that the average NPP in the African Savanna decreased by $2.13 \mathrm{gC} / \mathrm{m}^{2}$ per year from 1982 to 2010 [14]. Li et al. found that the NPP in global terrestrial ecosystems significantly increased from 1976 to 2005 and was sensitive to a warming climate [15]. This collection of studies suggests that during different time periods, using different data sets and different methods may result in contradictory results. Extreme weather events (such as heavy rain or drought events) caused forest NPP to drop by more than $25 \%$ [16-18]. Sun et al. concluded that drought events led to a decrease of $112.06 \mathrm{TgC}$ in NPP in the northern part of China from 1999 to 2013 [19]. While extreme weather events (drought and heavy rain events) decreased NPP, levels recovered to their original values through self-growth in, showing that NPP has elasticity or resilience.

There were relatively few studies on NPP in the mountainous vegetated regions of Qinling. However, there were studies conducted from individual tree species to ecosystem scales. $\mathrm{Li}$ et al. stated that the biomass of Larix chinensis forest in the north and south slopes of the Qinling Mountains increased from 1958 to 2008 [20]. Jiang et al. showed that the NPP in Qinling was lower than that of vegetation in Bashan from 1959 to 2010, and the NPP in the Hanjiang River Basin in southern Shaanxi showed a decreasing trend during the same time period [21-22]. Yuan et al. estimated that the annual average NPP from 1999 to 2008 was $542.24 \mathrm{gC} / \mathrm{m}^{2}$ using the CASA model [23]. Wang et al. indicated that the annual average NPP from 2000 to 2013 was $600 \mathrm{gC} / \mathrm{m}^{2}$ using MOD17A3 data [24]. These variations in results show that more research is needed to elucidate the response of NPP to climate in the Qinling Mountains using different analysis methods and models. As an important mountainous ecosystem in central and eastern China, more research is needed to strengthen the understanding of and provide theoretical and quantitative support for the coordinated development of mountain ecosystems and regional economic and social development. Based on GIMMS NDVI data, meteorological data, and DEM and vegetation type data, the comprehensive CASA model was used to simulate NPP and the response to climate change in the Qinling Mountains from 1982 to 2015. The objective of this study was to evaluate the applicability of the CASA model and to reveal the characteristics of changes in NPP in the Qinling Mountains and the relationships with air temperature and precipitation under the background of global warming.

\section{Materials and Methods}

\section{Study Area}

The Qinling Mountains are the boundary between the Yellow and the Yangtze Rivers and between the warm temperate and the subtropical zones. The study area was located between $105^{\circ} 30^{\prime} \mathrm{E}-111^{\circ} 05^{\prime} \mathrm{E}$ and $31^{\circ} 55^{\prime} \mathrm{N}-34^{\circ} 35^{\prime} \mathrm{N}$, with a total area of about $7 \times 10^{4} \mathrm{~km}^{2}$ (Fig. 1a). The climate gradient from the north to south of the mountain range was large, gradually transitioning from a warm temperate continental monsoon climate to a subtropical monsoon climate. Over that gradient, the annual precipitation increased from 500 to over 
$1000 \mathrm{~mm}$ and the average air temperature of the Qinling Mountains significantly diminished. From the foothills to the main peak of Taibai Mountain, the Baxiantai (3771.2 $\mathrm{m}$ above sea level), the vegetation experienced changes from evergreen broadleaf forest to mountain deciduous broad-leaved forest, mountain coniferous forest, alpine shrub, and alpine meadow. The differences in climate led to a large difference between the ecosystems on the northern and southern slopes. The north slope has steep mountains with short and rapid rivers, such as the Bahe and the Chanhe River. On the south slope, the mountain slopes are gentle and the rivers are long, such as the Hanjiang and Danjiang River. A mountain valley in the area was developed into a densely populated area. The Qinling Mountains became the water source for the Middle Rote Project of China's South-to-North Water Transfer Project in 2014, and the resulting changes in terrestrial ecosystems received more attention. From 1982 to 2015, the annual average air temperature and precipitation in the Qinling Mountains showed an increasing trend. The rates of increase were between $0.11^{\circ} \mathrm{C}-0.15^{\circ} \mathrm{C}$ and $9.86 \mathrm{~mm}-18.52 \mathrm{~mm}$, respectively. The increasing trends of air temperature and precipitation provided favorable conditions for the growth and development of vegetation in the Qinling Mountains.

\section{Data}

(1) Meteorological data and solar radiation. From 1982 to 2015 , data from a total of 22 meteorological stations were used from the Qinling Mountains and nearby areas (Fig. 1), with variables including monthly sunshine hours, sunshine percentage, average minimum air temperature, average maximum air temperature, average air temperature, average air pressure, average vapor pressure, average wind speed, average relative humidity, the number of days of daily precipitation $\geq 0.1 \mathrm{~mm}$, and precipitation amount. In addition, monthly data on total solar radiation from the Ankang station (1990-2015) and Xi'an station (1982-2015) were obtained and downloaded from the National Meteorological Information Center (http://data.cma.cn).

(2) Remote sensing. Global inventory modeling and mapping studies (GIMMS) NDVI3g v1.0 data used were from 15d of global NDVI from 1982 to 2015,

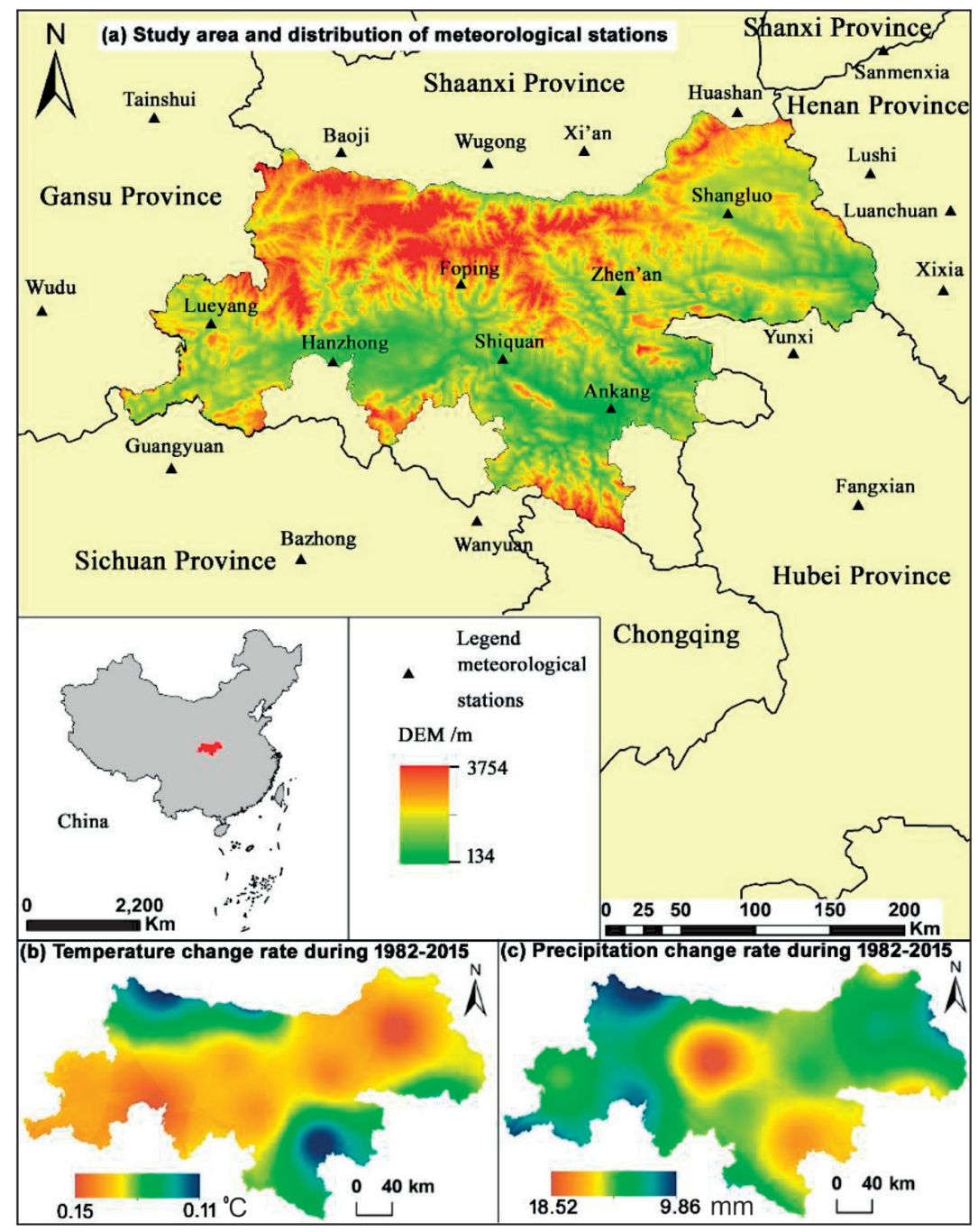

Fig. 1. a) Distribution of meteorological stations and the rate of change of b) temperature and c) precipitation during 1982-2015. 
downloaded from the Ecological Forecasting Lab at NASA Ames Research Center: https://ecocast.arc. nasa.gov/data/pub/gimms/, with a spatial resolution of $5 \mathrm{~km}$ (after resampling) and .nc4 standard format. MOD17A3 data included two resolutions: $1 \mathrm{~km}$ resolution from 2000 to 2015 and $500 \mathrm{~m}$ resolution from 2000 to 2014.

(3) DEM data with $30 \mathrm{~m}$ resolution. Data were downloaded from the National Science Data Mirroring Website of the Computer Network Information Center, Chinese Academy of Science (http://www.gscloud. cn). DEM was used to obtain air temperature spatial interpolation data using the Inverse Distance Weighted (IDW) method.

\section{Methods}

Since the 1970s, most models of NPP have used climate statistics such as general air temperature and precipitation, such as the early Miami model [25]. With more research, the Chikugo and Beijing models were developed [26-27]. The Comprehensive model is a climate-based model that uses more comprehensive variables to consider air temperature and precipitation, while CASA is a process model that also considers vegetation factors. In general, the accuracy of estimated NPP using the CASA model is higher. This paper uses these two models to calculate the NPP in the Qinling Mountains in order to compare the accuracy and to judge the applicability of the two models in the mountainous terrain.

\section{Comprehensive model}

Zhou et al. proposed a comprehensive model for NPP based on the regional evapotranspiration model according to the energy and water balance equation [28]. The calculation is:

$\mathrm{NPP}=R D I^{2} \times \frac{r \times\left(1+R D I+R D I^{2}\right)}{(1+R D I) \times\left(1+R D I^{2}\right)} \times \exp (-\sqrt{9.87+6.25 \times R D I})$

$$
R D I=\left(0.629+0.237 \times P E R-0.00313 \times P E R^{2}\right)^{2}
$$

$$
\begin{gathered}
P E R=\frac{P E T}{r}=B T \times 58.93 / r \\
B T=\sum \frac{t_{d}}{365} \text { or }=\sum T_{m} / 12
\end{gathered}
$$

...where RDI is the radiation dryness; $r$ is the annual precipitation, $\mathrm{mm}$; PER is the potential evapotranspiration rate, \%; and PET is the potential evapotranspiration amount, $\mathrm{mm}$. BT is the annual average biological temperature, ${ }^{\circ} \mathrm{C}$; $\mathrm{t}_{\mathrm{d}}$ is the daily average air temperature between $<30^{\circ} \mathrm{C}$ and $>0{ }^{\circ} \mathrm{C}$; and $\mathrm{T}_{\mathrm{m}}$ is the monthly average air temperature between $<30^{\circ} \mathrm{C}$ and $>0{ }^{\circ} \mathrm{C}$.

Three different results for NPP in the Qinling Mountains were obtained through the use of the comprehensive model and air temperature interpolation data. The spatial resolution of NPP was $250 \mathrm{~m}$ from 1982 to 2015 . The calculation process is shown in Fig. 2.

\section{CASA Model}

The CASA model was proposed by Potter et al. and was determined by two factors: the level of photosynthetically active radiation (APAR) and the light energy utilization efficiency $(\varepsilon)$ [29]. The formula is:

$$
\operatorname{NPM}(x, m)=\operatorname{APAR}(x, m) \times m
$$

...where $\operatorname{NPP}(x, m)$ is the net primary productivity of pixel $x$ in month $\mathrm{m}, \mathrm{gC} / \mathrm{m}^{2} ; \operatorname{APAR}(x, m)$ is the photosynthetically active radiation of pixel $x$ in month $\mathrm{m}$, $\mathrm{MJ} / \mathrm{m}^{2}$; and $\varepsilon(x, m)$ is the actual light energy utilization of pixel $x$ in month $\mathrm{m}, \mathrm{gC} / \mathrm{MJ}$.

The formula for calculating photosynthetically active radiation (APAR) is:

$$
\operatorname{APAR}(x, m)=S(x, m) \times \operatorname{FPAR}(x, m)
$$

...where $\mathrm{S}(x, m)$ is the total solar radiation amount of the pixel $x$ in the month of $\mathrm{m}, \mathrm{MJ} / \mathrm{m}^{2}$, calculated using the solar radiation calculation formula and interpolated. The solar radiation calculation formula is:

$$
d=1+0.033 \times \cos (2 \pi \times d n / 365)
$$

$$
\text { chiwei }=\text { fai } \times \frac{\pi}{180}-\operatorname{acos}(\sin (h \times \pi / 180))
$$

shijiao $=\operatorname{acos}(-\tan ($ fai $\times \pi / 180) \times \tan ($ chiwei $))$

$$
\begin{aligned}
R_{s}= & 1366.0 \times 24 \times 60 \times 60 \times d / \pi \times\left(\text { shijiao } \times \sin \times \frac{\pi}{180}\right) \times \sin (\text { chiwe }) \\
& +\cos (\text { fai } \times \pi / 180) \times \cos (\text { chiwei }) \times \sin (\text { shijiao }))
\end{aligned}
$$

...where $d$ is the distance from the sun to the earth on a certain day in the local area; chiwei is the sun declination; shijiao is the local sunset angle; $R s$ is the theoretical daily solar radiation; $d n$ is the day of the year number; fai is the local latitude; and $h$ is the midday sun height. Monthly theoretical total solar radiation was summed using daily solar radiation, and the actual monthly solar radiation was obtained by multiplying the percentage of the station's monthly sunshine time by the theoretical monthly solar radiation. 


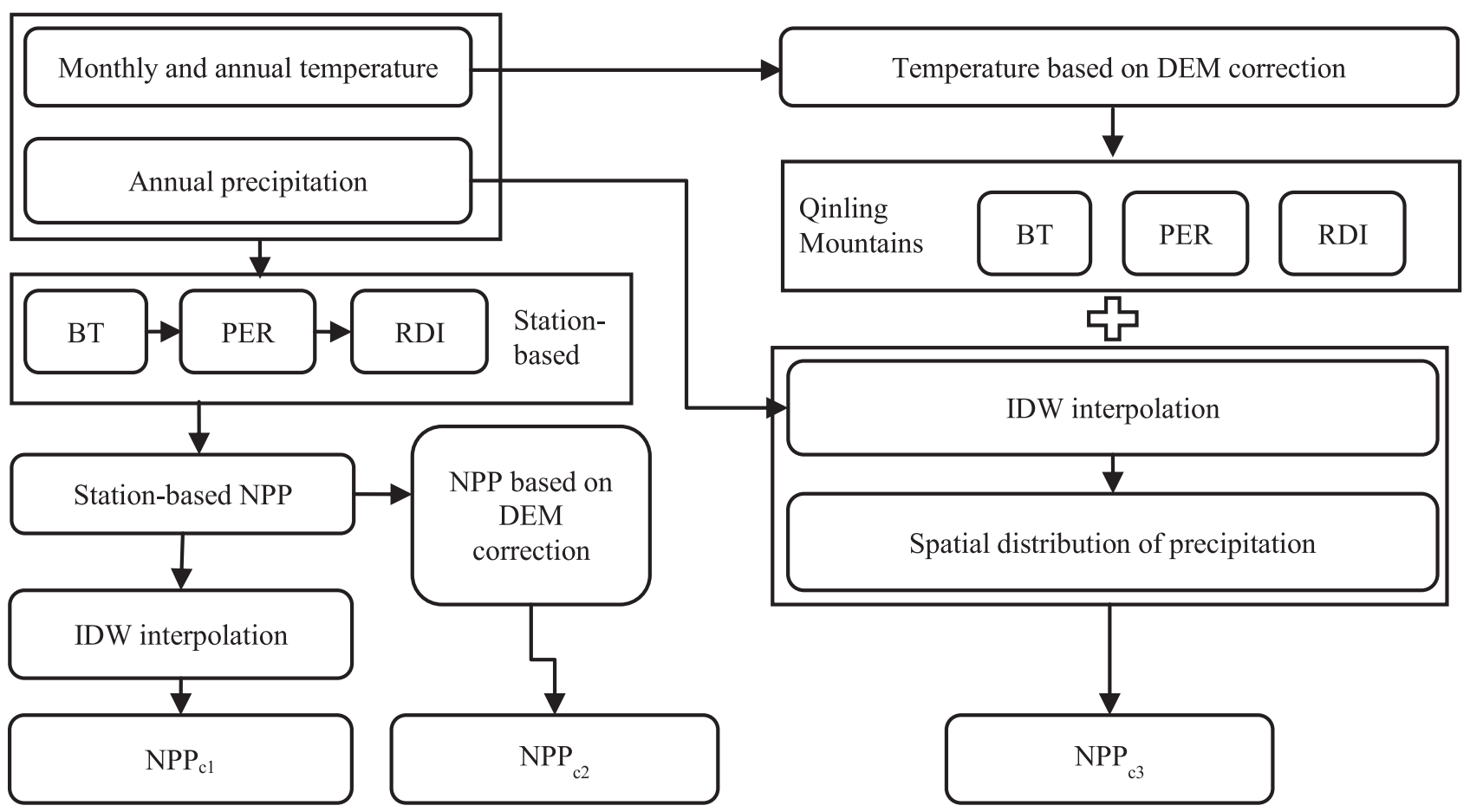

Fig. 2. The NPP calculation process using the comprehensive model. RDI is the radiation dryness; PER is the potential evapotranspiration rate; and $\mathrm{BT}$ is the annual average biological temperature.

$\operatorname{FPAR}(x, m)$ is the absorption coefficient of the effective radiation emitted by the vegetation canopy and is calculated using the following formula:

$\operatorname{FPAR}(x, m)=\frac{\operatorname{NDVI}(x, m)-\mathrm{NDVI}_{\text {min }}}{\mathrm{NDVI}_{\text {max }}-\mathrm{NDVI}_{\text {min }}} \times 0.94+0.01$

...where $\mathrm{NDVI}_{\text {min }}$ and $\mathrm{NDVI}_{\text {max }}$ are the minimum and maximum value of NDVI, respectively.

The light energy utilization efficiency $(\varepsilon)$ is the efficiency of the photosynthetically active radiation absorbed by the vegetation into organic carbon, $\mathrm{gC} / \mathrm{MJ}^{2}$, calculated as:

$$
\varepsilon(x, m)=T_{\varepsilon 1}(x, m) \times T_{\varepsilon 2}(x, m) \times W_{\varepsilon}(x, m) \times \varepsilon_{\max }
$$

....where $\mathrm{T}_{\varepsilon 1}(x, m)$ and $\mathrm{T}_{\varepsilon 2}(x, m)$ are the coefficients of low air temperature and high air temperature on the utilization efficiency of light energy, respectively. $T_{\varepsilon 1}$ is the photosynthetic limitation of plant biochemical action under lower and higher air temperature, calculated as follows:

$$
T_{\varepsilon 1}(x, \mathrm{~m})=0.8+0.02 \times T_{o p t}(x)-0.0005 \times\left[T_{o p t}(x)\right]^{2}
$$

...where $\mathrm{T}_{\mathrm{opt}}(x, m)$ is the average air temperature in the month when the NDVI value reached the maximum in the study area within one year, ${ }^{\circ} \mathrm{C} \mathrm{T}_{\varepsilon 2}$ is the gradual decreasing trend of the utilization efficiency of vegetation light energy, when the ambient air temperature changed from the optimum air temperature to a high or low air temperature, calculated as:

$$
\begin{aligned}
T_{\varepsilon 2}(x, m) & =\frac{1.1814}{1+\exp \left[0.2 \times\left(T_{o p t}(x)-10-T(x, m)\right)\right]} \\
& \times \frac{1}{1+\exp \left[0.3 \times\left(-T_{o p t}(x)-10+T(x, m)\right)\right]}
\end{aligned}
$$

...where $\mathrm{T}(\mathrm{x}, \mathrm{m})$ is the average air temperature of month m.

$\mathrm{W}_{\varepsilon}(x, m)$ is the coefficient of water stress, which indicated the influence of water on the utilization efficiency of light energy. The value range was between 0.5 (extreme drought) and -1 (extreme wetness), calculated as:

$$
\mathrm{W}_{\varepsilon}(x, m)=0.5+0.5 \times \operatorname{EET}(x, m) / \operatorname{PET}(x, m)
$$

...where $\operatorname{EET}(x, m)$ is the actual evapotranspiration, $\mathrm{mm}$; and $\operatorname{PET}(x, m)$ is the potential evapotranspiration, $\mathrm{mm}$. PET was calculated using the Penman-Monteith Combination model developed by the Food and Agriculture Organization of the United Nations (FAO) [30-31].

$$
P E T=\frac{0.408 \times \Delta \times R_{n}+\gamma \times \frac{900}{T+273} U_{2}\left(e_{s}-e_{a}\right)}{\Delta+\gamma \times\left(1+0.34 \times U_{2}\right)}
$$


...where PET is the potential evapotranspiration, $\mathrm{mm} / \mathrm{d}$; $\mathrm{R}_{\mathrm{n}}$ is the net radiation, $\mathrm{MJ} /\left(\mathrm{m}^{2} \cdot \mathrm{d}\right) ; \gamma$ is the dry and wet constant, $\mathrm{kPa} /{ }^{\circ} \mathrm{C}$; $\mathrm{T}$ is the average air temperature, ${ }^{\circ} \mathrm{C}$; $\mathrm{U}_{2}$ is the average wind speed at a height of $2 \mathrm{~m}$ from the ground, $\mathrm{m} / \mathrm{s} ; \mathrm{e}_{\mathrm{a}}$ is the actual water average vapor pressure, $\mathrm{kPa}$; $\mathrm{e}_{\mathrm{s}}$ is the average saturated water vapor pressure, $\mathrm{kPa}$; and $\Delta$ is the saturated water vapor pressure curve rate, $\mathrm{kPa} /{ }^{\circ} \mathrm{C}$. The formula to calculate each parameter is as follows:

$$
\begin{aligned}
R_{n}= & 0.77 \times R_{s}-\sigma \times\left[\frac{\left(T_{\max }+273\right)^{4}+\left(T_{\min }+273\right)^{4}}{2}\right] \\
& \times\left(0.56-0.25 \times \sqrt{e_{a}}\right) \times\left(0.1+0.9 \times \frac{n}{N}\right)
\end{aligned}
$$

...where $\mathrm{R}_{\mathrm{s}}$ is solar radiation, $\mathrm{MJ} / \mathrm{m}^{2}$, the calculation method is mentioned above; $\sigma$ is the Stephen-Boltzman constant, $4.903 \times 10^{-9} \mathrm{MJ} /\left(\mathrm{K}^{4} \cdot \mathrm{m}^{2} \cdot \mathrm{d}\right) ; \mathrm{T}_{\max }$ and $\mathrm{T}_{\min }$ are the highest and lowest air temperatures, respectively, ${ }^{\circ} \mathrm{C} ; \mathrm{n}$ is the actual sunshine hours, $\mathrm{h}$; and $\mathrm{N}$ is the illuminable hours, h.

$$
\Delta=\frac{4098 \times\left[0.6108 \times \exp \left(\frac{17.27 \times T}{T+237.3}\right)\right]}{(T+237.3)^{2}}
$$

...where $\mathrm{T}$ is the average air temperature, ${ }^{\circ} \mathrm{C}$

$$
\begin{gathered}
e_{s}=0.3054 \times\left[\exp \left(\frac{17.27 \times T_{\max }}{T_{\max }+237.3}\right)+\exp \left(\frac{17.27 \times T_{\min }}{T_{\min }+237.3}\right)\right] \\
e_{a}=e_{s} \times R H
\end{gathered}
$$

...where $\mathrm{RH}$ is average relative humidity, \%.

$$
\begin{gathered}
\gamma=0.665 \times P \\
P=101.3 \times\left(\frac{293-0.0065 \times z}{293}\right)^{5.26}
\end{gathered}
$$

...where $\mathrm{P}$ is average air pressure, $\mathrm{kPa}$; and $\mathrm{z}$ is altitude, $\mathrm{m}$.

$$
U_{2}=U_{z} \frac{4.87}{\ln (67.8 \times z-5.42)}
$$

...where $\mathrm{U}_{\mathrm{z}}$ is the average wind speed at the height $\mathrm{z} \mathrm{m}$ from the ground, $\mathrm{m} / \mathrm{s}$.

The daily potential evapotranspiration is obtained according to the formula mentioned above. The monthly potential evapotranspiration is calculated by multiplying the daily value to the number of days per month, and the annual value is obtained by summing the monthly values.
EET was estimated according to an empirical formula proposed by Takahashi Koichiro [32]:

$$
\mathrm{EET}=\frac{A \times R M}{A+B \times R M^{2} \times \exp \left(-\frac{C \times t}{235+t}\right)}
$$

...where $A, B$ and $C$ are empirical coefficients, which were $3100,1.8$ and 34.4 , respectively. $R M$ is the monthly precipitation, and $t$ is the monthly average temperature.

$\varepsilon_{\max }$ represents the maximum light energy utilization efficiency. Because $\varepsilon_{\max }$ was related to the type of vegetation, $\varepsilon_{\max }$ could be determined according to the results of Zhu et al. [33]. The value for an evergreen coniferous forest is $1.009 \mathrm{gC} / \mathrm{MJ} ; 1.259 \mathrm{gC} / \mathrm{MJ}$ for an evergreen broadleaf forest; $1.103 \mathrm{gC} / \mathrm{MJ}$ for a deciduous coniferous forest; $1.044 \mathrm{gC} / \mathrm{MJ}$ for a deciduous broad-leaved forest; $1.116 \mathrm{gC} / \mathrm{MJ}$ for a mixed forest; $0.768 \mathrm{gC} / \mathrm{MJ}$ for deciduous shrub and savanna grassland; $0.608 \mathrm{gC} / \mathrm{MJ}$ for grassland; $0.604 \mathrm{gC} / \mathrm{MJ}$ for cultivated vegetation; and others, such as cities and water bodies, are $0.389 \mathrm{gC} / \mathrm{MJ}$, which was the global average light utilization efficiency estimated by the CASA model.

Two kinds of NPP were calculated using the CASA model, GIMMS NDVI, and the vegetation type on the Qinling Mountains in 2010. The spatial resolution of NPP was $5 \mathrm{~km}$ from 1982 to 2015. The calculation process is shown in Fig. 3.

NPP1km and NPP500m were calculated from 20002014 using a more complex ecological coupling model, and their responses to climate change and reliability have been verified [34-35], but due to the shorter time scale they did not meet the requirements for long-term sequence studies. GIMMS NDVI and meteorological data combined with the CASA model were used to calculate long-term NPP results (1982-2015) and verified using NPP1 km and NPP500 $\mathrm{m}$.

\section{Results}

\section{Comparison of NPP Calculations}

The average NPP in the Qinling Mountains obtained from MOD17A3 from 2000-2014 was compared and analyzed as calculated by different models (Fig. 4).

Fig. 4 shows that the average value of $\mathrm{NPP}_{\mathrm{cg}}$ during 2000-2014 was between the average value of NPP1km and NPP500m during the same period. The average value of $\mathrm{NPP}_{\mathrm{cg}}$ was $35.60 \mathrm{gC} / \mathrm{m}^{2}$ lower than the average value of NPP $500 \mathrm{~m}$, accounting for about $5.3 \%$ of the average value of NPP500m, which indicated that NPP was more reliable than $\mathrm{NPP}_{\mathrm{cl}}, \mathrm{NPP}_{\mathrm{c} 2}, \mathrm{NPP}_{\mathrm{c} 3}$, and $\mathrm{NPP}_{\mathrm{cgv}}{ }^{\mathrm{cg}}$.

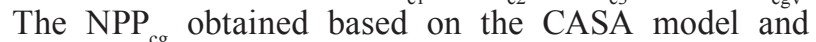
GIMMS NDVI could be used to look into the temporal and spatial variation of NPP in the Qinling Mountains 


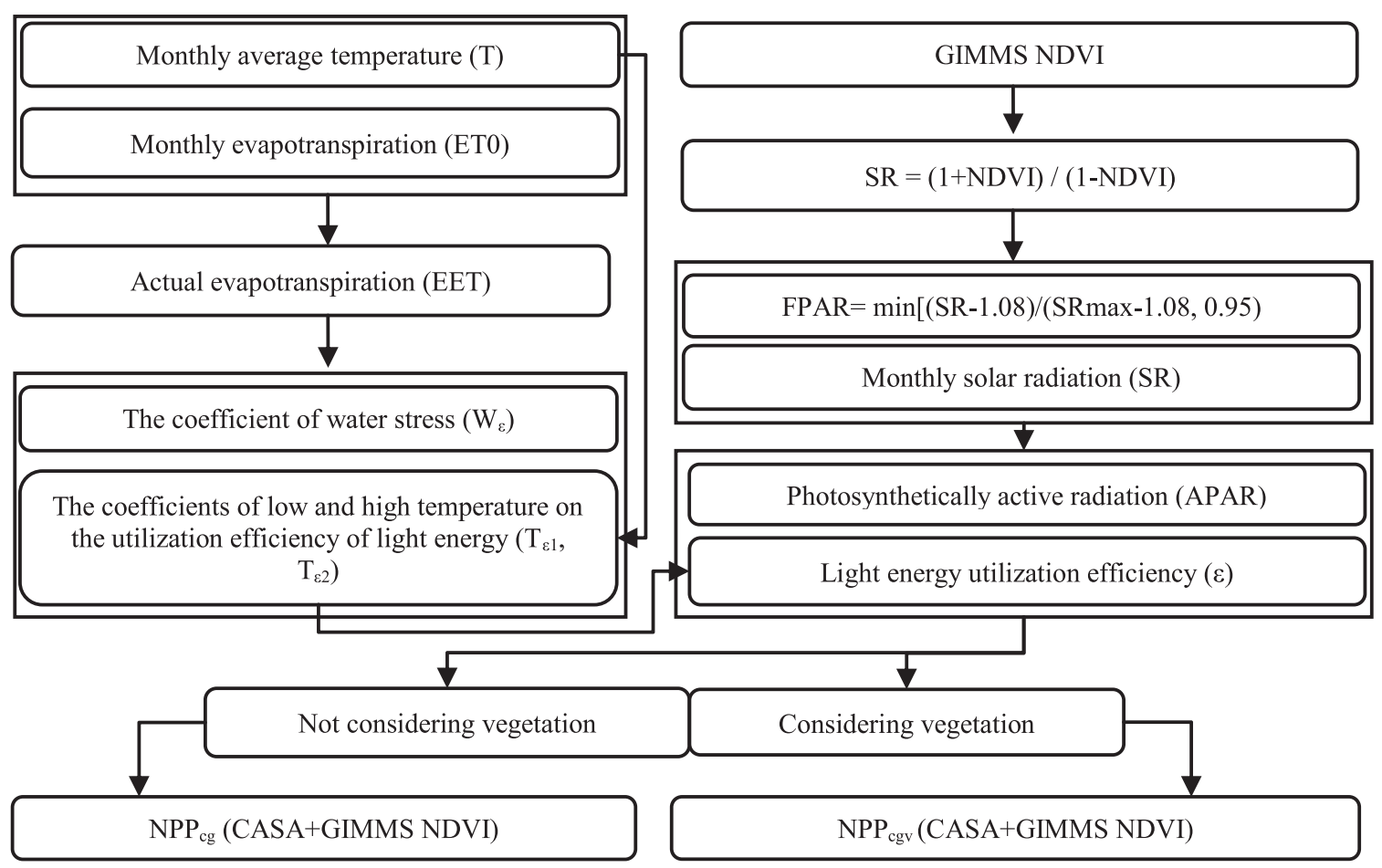

Fig. 3. The NPP calculation process using the CASA model. FPAR is the absorption coefficient of the effective radiation emitted by the vegetation canopy. NDVI is the normalized difference vegetation index.

and its responses to changes in air temperature and precipitation.

\section{Temporal Changes of NPP in the Qinling Mountains}

The annual average NPP in the Qinling Mountains generally increased over the period of analysis. The critical year emerged as 1998, with the multi-year average value of NPP increasing from $592.36 \mathrm{gC} / \mathrm{m}^{2}$ (1982-1998) to $617.63 \mathrm{gC} / \mathrm{m}^{2}$ (1999-2015), an increase of $4.3 \%$. In the aspect of change rate, NPP increased from

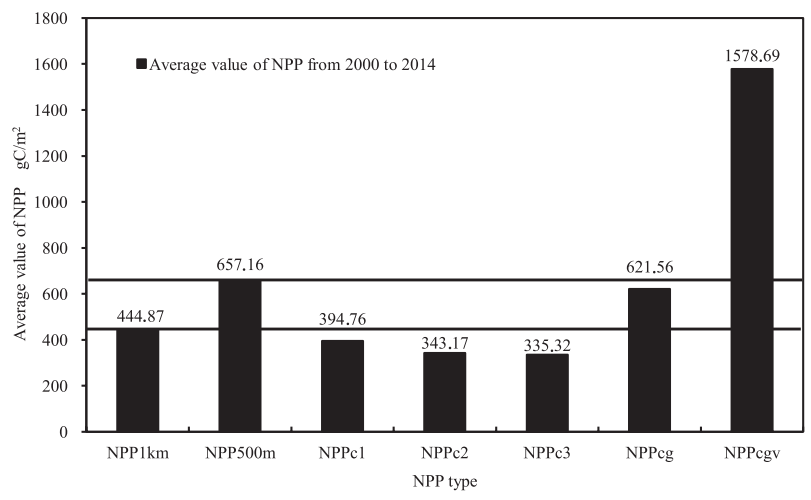

Fig. 4. The multi-year average value of NPP with different calculation methods. Different types of NPP labels are explained in Fig. 2 and Fig. 3. Note: The upper horizontal line in the figure corresponds to the NPP500m annual average NPP value line for 2000-2014, while the lower horizontal line corresponds to the NPP1 km annual average NPP value for 2000-2014.
1982 to 2015 at a rate of $1.2518 \mathrm{gC} / \mathrm{m}^{2}$, but the rate was insignificant (Fig. 5a, Table 1).

In the study area, seasons were defined as spring from March to May, summer from June to August, autumn from September to November, and winter from December to February of the following year. In descending order, the seasonal multi-year average of NPP from 1982 to 2015 was: summer $\left(339.36 \mathrm{gC} / \mathrm{m}^{2}\right)$ $>$ spring $\left(129.10 \mathrm{gC} / \mathrm{m}^{2}\right)>$ autumn $\left(127.25 \mathrm{gC} / \mathrm{m}^{2}\right)>$ winter $\left(10.43 \mathrm{gC} / \mathrm{m}^{2}\right)$. Except for the linearly decreasing trend in winter $\left(-0.0507 \mathrm{gC} /\left(\mathrm{m}^{2} \cdot \mathrm{a}\right)\right)$, the rate increased in spring (1.1141 $\left.\mathrm{gC} /\left(\mathrm{m}^{2} \cdot \mathrm{a}\right)\right)$, summer $\left(0.1715 \mathrm{gC} /\left(\mathrm{m}^{2} \cdot \mathrm{a}\right)\right)$, and autumn $\left(0.0041 \mathrm{gC} /\left(\mathrm{m}^{2} \cdot \mathrm{a}\right)\right)$. The growth rate of NPP in spring vegetation was higher than that in summer (Fig. 5b, Fig. 5c, Fig. 5d, Fig. 5e, Table 1).

\section{Spatial Changes of NPP in the Qinling Mountains}

\section{Spatial Changes in Annual NPP}

From 1982 to 2015, the annual variation of NPP in Qinling Mountain vegetation was dominated by an increasing trend that accounted for $64.92 \%$ of the total area. The significant portion was concentrated in the southeastern study area and accounted for $35.49 \%$ of the area. The significant decreasing trend was distributed in the western part of the study area from the south to north and accounted for $10.83 \%$ of the area (Fig. 6a, Table 1). The change rate was between $-6.93 \mathrm{gC} /\left(\mathrm{m}^{2} \cdot \mathrm{a}\right)$ and $8.57 \mathrm{gC} /\left(\mathrm{m}^{2} \cdot \mathrm{a}\right)$. Among the regions with decreasing 


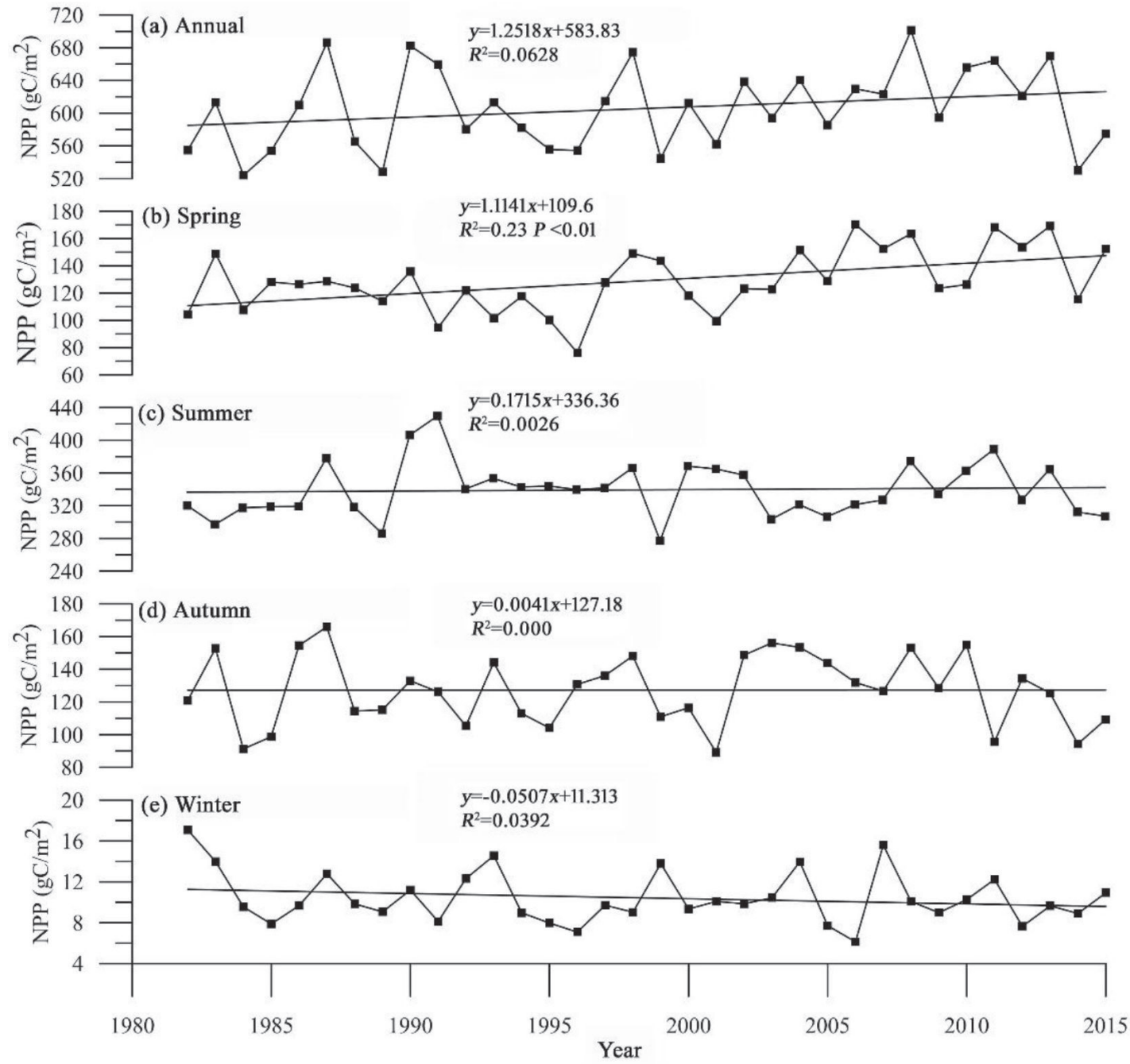

Fig. 5. Annual and seasonal NPP changes in the Qinling Mountains from 1982 to 2015.

trends, the central and western regions (the Hanzhong Basin) had the largest rate of decline (Fig. 6b, Table 1).

\section{Spatial Changes in Seasonal NPP}

From 1982 to 2015, the trend in spring NPP mainly increased, accounting for $89.90 \%$ of the total area, of which the significantly increasing trend was concentrated in the middle and east of the study area and accounted for $57.84 \%$. The decreasing trend accounted for $10.10 \%$, of which $1.71 \%$ was significant and concentrated in the vicinity of Hanzhong City in the southwest of the study area (Fig. 6c, Table 1). The rate of change of the spring NPP was between

Table 1. Statistics of the NPP change trend.

\begin{tabular}{|c|c|c|c|c|}
\hline Period & Sig. increase (\%) & Increase (\%) & Decrease (\%) & Sig. decrease (\%) \\
\hline Inter-annual & 35.49 & 29.43 & 24.25 & 10.83 \\
\hline Spring & 57.84 & 32.06 & 8.39 & 1.71 \\
\hline Summer & 18.78 & 31.95 & 34.86 & 3.41 \\
\hline Autumn & 5.65 & 47.81 & 39.54 & 7.00 \\
\hline Winter & 0.77 & 32.13 & 44.23 & 22.87 \\
\hline
\end{tabular}

At the pixel scale, the NPP change rate was divided into two categories: increasing and decreasing, and the calculated $F$-test results were divided into significant and insignificant categories according to the threshold value (For $\mathrm{n}=34$ samples and an $\alpha=0.05$, the threshold value was 4.15.). Finally, the change rate and the $F$-test result were overlaid and the NPP change trend was divided into four categories: significant/insignificant increase or significant/insignificant decrease. Methods of calculation can be found in [36]. 

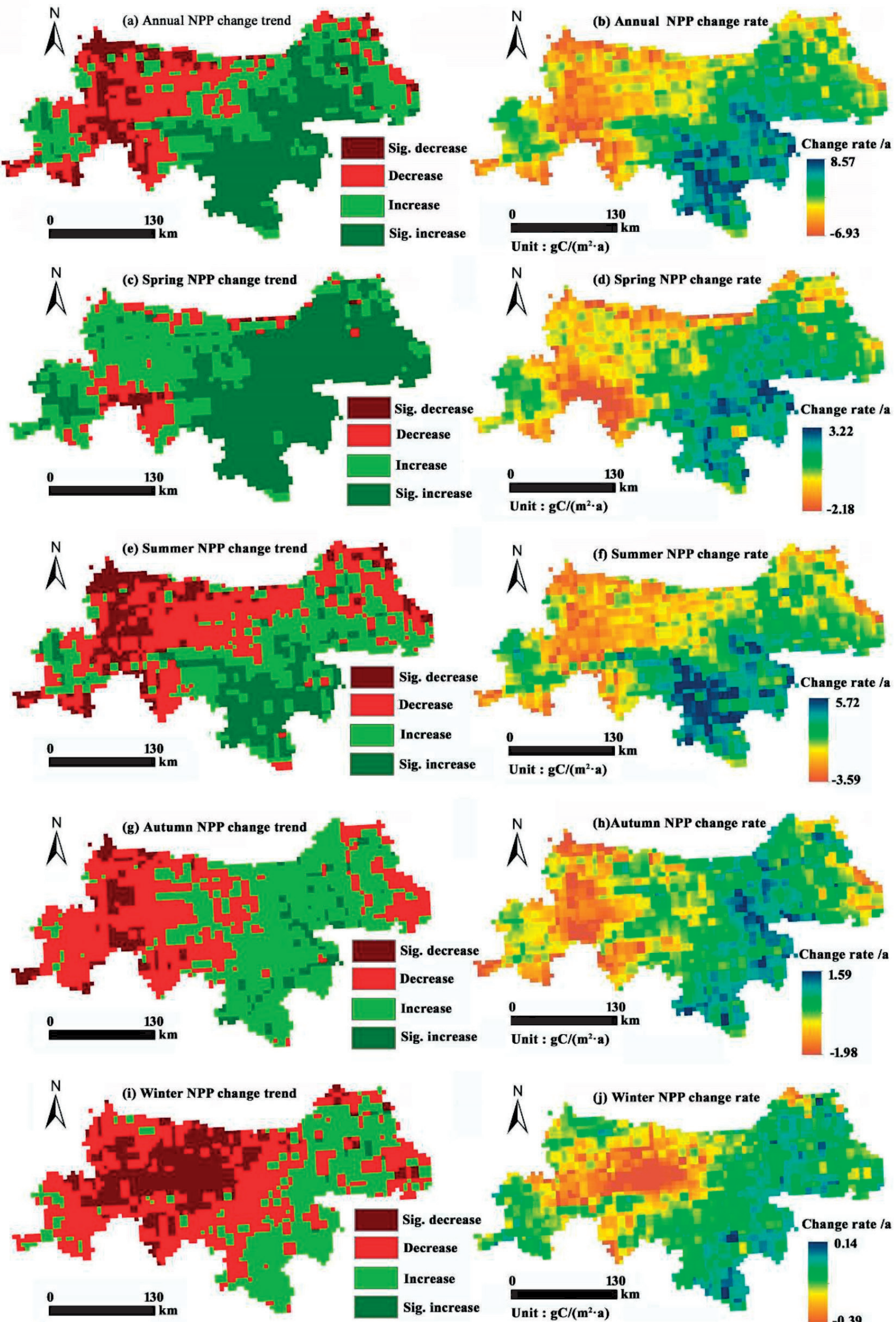

Fig. 6. Spatial distribution of NPP change trends and rates at annual (a, b), spring (c, d), summer (e, f), autumn (g, h) and winter (i, j) scales in the Qinling Mountains from 1982 to 2015. Note: Based on the threshold value (For $n=34$ samples and an $\alpha=0.05$, the threshold value was 4.15), and change rate (the threshold value was 0 ), the change trend was classified into four: significant decrease, decrease, increase and significant increase. 
-2.18 $\mathrm{gC} /\left(\mathrm{m}^{2} \cdot \mathrm{a}\right)$ and $3.22 \mathrm{gC} /\left(\mathrm{m}^{2} \cdot \mathrm{a}\right)$. In the areas with increasing trends, NPP increased fastest in the southeast, while it decreased the most rapidly at the boundary between Hanzhong Basin, Qinling North, and the Guanzhong Plain (Fig. 6d, Table 1).

The summer NPP mainly showed an increasing trend, accounting for $50.73 \%$ of the total area. The significantly increasing areas were mainly distributed in the southeast and accounted for $18.78 \%$ of the total of the study area. The decreasing areas were concentrated in the northwest region and accounted for $49.27 \%$, of which $14.41 \%$ was significant (Fig. 6e, Table 1). The rate of change of NPP was between $-3.59 \mathrm{gC} /\left(\mathrm{m}^{2} \cdot \mathrm{a}\right)$ and $5.72 \mathrm{gC} /\left(\mathrm{m}^{2} \cdot \mathrm{a}\right)$. Within the increasing trend's range, the highest rate of change was concentrated in the southeast (around the Ankang Basin), while the highest decreasing rate of change was concentrated in a large area between Hanzhong and Baoji in the northwest (Fig. 6f, Table 1).

The autumn NPP mainly increased, accounting for $53.46 \%$ of the total area, of which $5.65 \%$ significantly increased in the eastern part of the study area. The decreasing trend accounted for $46.54 \%$, of which $7.00 \%$ was significant, concentrated in the western part of the study area (Fig. 6g, Table 1). The NPP rate of change was between $-1.98 \mathrm{gC} /\left(\mathrm{m}^{2} \cdot \mathrm{a}\right)$ and $1.59 \mathrm{gC} /\left(\mathrm{m}^{2} \cdot \mathrm{a}\right)$. The increasing trends and the highest rate of change were mainly distributed in the eastern region, while the lower values were concentrated in the west (Fig. 6h, Table 1).

In winter, the NPP trend mainly decreased, accounting for $67.10 \%$ of the total area, of which $22.87 \%$ was significant, concentrated in the central and western regions. The increasing trend accounted for $32.90 \%$ of the area, of which $0.77 \%$ was significant and lacked an obvious distribution (Fig. 6i, Table 1). The rate of change of NPP was between $-0.39 \mathrm{gC} /\left(\mathrm{m}^{2} \cdot \mathrm{a}\right)$ and $0.14 \mathrm{gC} /\left(\mathrm{m}^{2} \cdot \mathrm{a}\right)$, with the highest rates of increase concentrated in the eastern regions showing a scattered distribution, while the highest rates of decrease were concentrated in the central area, especially the Taibai Mountains and south to the Hanjiang Valley (Fig. 6j, Table 1).

\section{Response of Annual NPP to Climatic Factors}

\section{Response of Annual NPP to Climatic Factors}

From 1982 to 2015, NPP was negatively correlated with annual average temperature, accounting for $60.84 \%$ of the total area, of which $9.43 \%$ was significant, mainly distributed in the southwest region. Positively correlated areas accounted for $39.16 \%$, of which the significant area was concentrated in the southeast and accounted for $3.45 \%$ (Fig. 7a, Table 2). The annual NPP and annual precipitation were positively correlated, accounting for $70.24 \%$, of which $31.23 \%$ was significant, distributed in the east with a northeast-southwest distribution. The negatively correlated area was $29.76 \%$, mainly distributed in the west, of which $2.97 \%$ was significant (Fig. 7b, Table 2).

\section{Response of Seasonal NPP to Climatic Factors}

The spring NPP was positively correlated with the average spring temperature, accounting for $90.68 \%$ of the total area, of which $10.83 \%$ was significant. The negatively correlated area was only $9.32 \%$, mainly distributed in the northern part of the study area, showing an east-west band distribution near the Hanzhong Basin in the southwest (Fig. 7c, Table 2). The spring NPP was positively correlated with spring precipitation, accounting for $82.60 \%$ of the total area, of which $21.25 \%$ was significant, concentrated in the northeastern part of the study area. Negatively correlated areas accounted for $17.39 \%$, distributed in the central and western regions with a south-north distribution (Fig. 7d, Table 2). The summer NPP was positively correlated with the summer average temperature, accounting for $79.49 \%$ of the total area, of which $1.32 \%$ was significant, while the negatively correlated area accounted for $20.51 \%$, which was concentrated in the northeastern part of the study area. There was no significant negative correlation distribution (Fig. 7e, Table 2). The summer NPP was negatively correlated with summer precipitation, accounting for $59.96 \%$ of the total area, of which $5.87 \%$ was significant and concentrated in the west and scattered in the northern and southwestern margins of the region. The positively correlated areas accounted for $40.03 \%$, of which $2.31 \%$ was significant, scattered in the southeast (Fig. 7f, Table 2).

The autumn NPP was positively correlated with the average temperature in autumn, accounting for $69.80 \%$ of the total area, of which $10.24 \%$ was significant, mainly distributed in the eastern region. The negatively correlated area was $30.21 \%$, with only $0.15 \%$ significant concentrated in the western part (Fig. 7g, Table 2). The autumn NPP was positively correlated with autumn precipitation, accounting for $52.36 \%$ of the area, of which $1.28 \%$ was significant, while the negative correlation accounted for $47.63 \%$, distributed in the middle and west of the study area, with only $0.44 \%$ significant area (Fig. 7 h, Table 2). The winter NPP was negatively correlated with the winter average temperature, accounting for $63.01 \%$ of the total area, mainly distributed in the central and western parts of the study area, of which $6.79 \%$ was significant. The positively correlated areas accounted for $36.99 \%$, distributed at the eastern edge with a northsouth distribution and only $0.70 \%$ significance (Fig. 7i, Table 2). The winter NPP was positively correlated with winter precipitation, accounting for $54.98 \%$ of the total area, mainly distributed in the central and northern parts of the study area and only $0.70 \%$ significance. The negative correlation accounted for $45.03 \%$ of the area, distributed in the southeast and southwest of the study area (Fig. 7j, Table 2). 

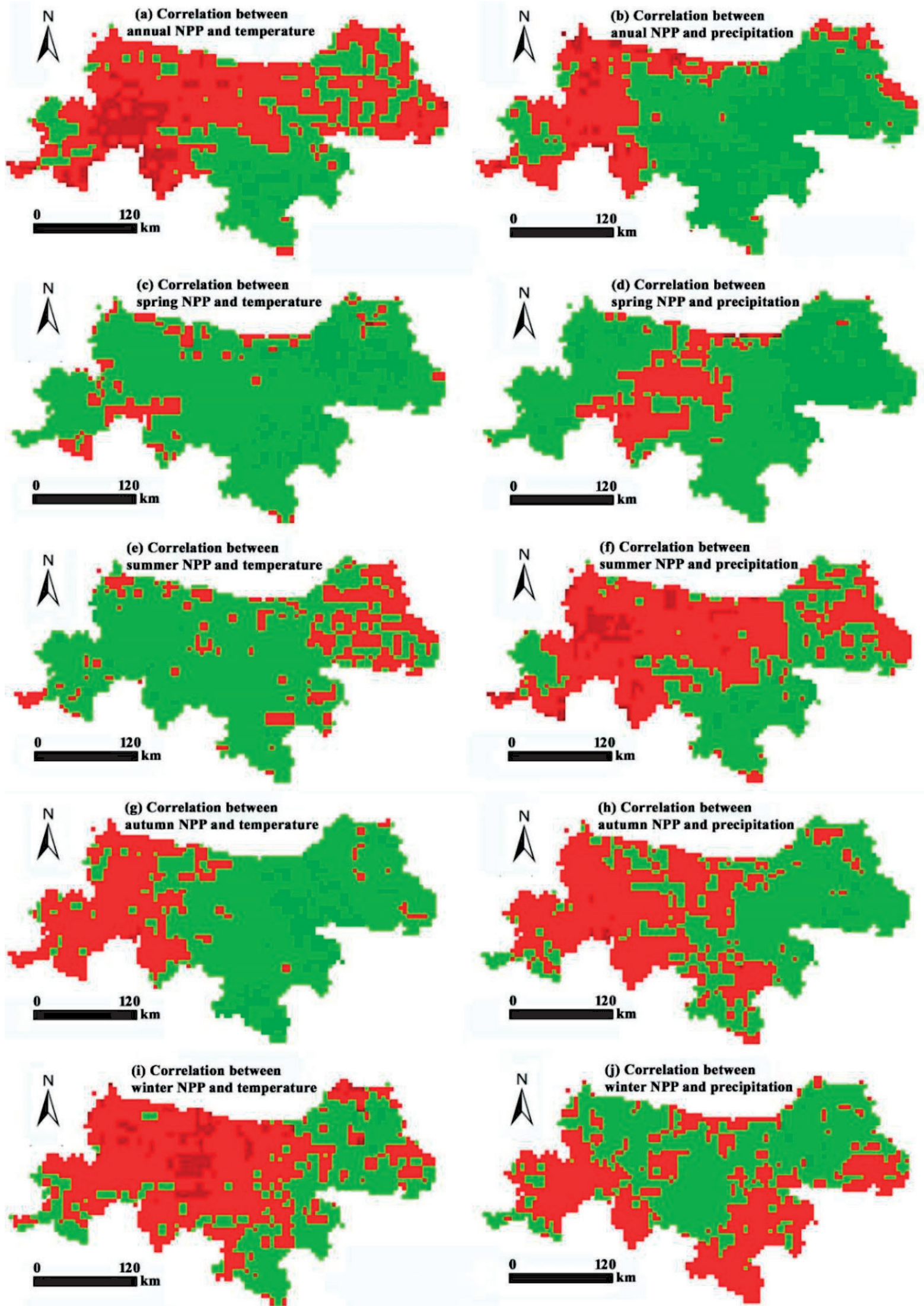

Correlation relationship

$\square$ sig. negative correlation negative correlation positive correlation sig. positive correlation

Fig. 7. Spatial distribution of the correlation between NPP and temperature or precipitation at annual (a, b), spring (c, d), summer (e, f), autumn (g, h) and winter (i, j) scales in the Qinling Mountains from 1982 to 2015 . Note: Based on the threshold value of correlation coefficient (For $\mathrm{n}=34$ samples and an $\alpha=0.05$, the threshold value was 0.3494 .), the correlation coefficient was divided into significant (sig.) negative correlation ( $\mathrm{r}<-0.3494)$, negative correlation $(-0.3494<\mathrm{r}<0)$, positive correlation $(0<\mathrm{r}<0.3494)$, and significant (sig.) positive correlation $(\mathrm{r}>0.3494)$. 
Table 2. Correlation statistics between NPP and the annual average air temperature and annual precipitation.

\begin{tabular}{|c|c|c|c|c|c|c|}
\hline \multirow{2}{*}{ Climate factors } & Item & Inter-annual & Spring & Summer & Autumn & Winter \\
\hline \multirow{4}{*}{$\begin{array}{c}\text { Annual average air } \\
\text { temperature }\end{array}$} & Sig. positive correlation (\%) & 3.45 & 10.83 & 1.32 & 10.24 & 0.70 \\
\cline { 2 - 7 } & Positive correlation (\%) & 35.71 & 79.85 & 78.17 & 59.56 & 36.29 \\
\cline { 2 - 7 } & Negative correlation (\%) & 51.41 & 9.25 & 20.51 & 30.06 & 56.22 \\
\cline { 2 - 8 } & Sig. negative correlation (\%) & 9.43 & 0.07 & 0.00 & 0.15 & 6.79 \\
\cline { 2 - 8 } Annual precipitation & Sig. positive correlation (\%) & 31.23 & 21.25 & 2.31 & 1.28 & 0.70 \\
\cline { 2 - 8 } & Positive correlation (\%) & 39.01 & 61.35 & 37.72 & 51.08 & 54.28 \\
\cline { 2 - 7 } & Negative correlation (\%) & 26.79 & 17.06 & 54.09 & 47.19 & 45.03 \\
\cline { 2 - 7 } & Sig. negative correlation (\%) & 2.97 & 0.33 & 5.87 & 0.44 & 0.00 \\
\hline
\end{tabular}

Taking the correlation coefficient of zero as the boundary, the correlation between NPP and annual average air temperature and precipitation was divided into positive correlation and negative correlation. Then, according to the threshold value (For $\mathrm{n}=34$ samples and an $\alpha=0.05$, the threshold value was 0.3494 .) of the correlation coefficient, the positive and negative correlations were divided into four categories: significant/insignificant correlation or significant/insignificant correlation. Methods of calculation can be found in [36].

\section{Discussion}

In this study, NPP was calculated using both remote sensing data and meteorological data. The linear trend and correlation coefficient methods were used to analyze the annual and seasonal NPP change trends and their relationship with climatic factors. More consideration of the findings of this study are needed in the following aspects:

(1) Jiang et al. indicated that the NPP estimated by the comprehensive model was also lower than the measured NPP value [37]. Yuan et al. and Zhang et al. calculated the annual average NPP with CASA model in the Qinling Mountains based on $1 \mathrm{~km}$ resolution SPOT NDVI data from 1999-2009 and MODIS NDVI data from 2000 to 2013, respectively [38]. The annual average NPP values they found were $543.34 \mathrm{gC} / \mathrm{m}^{2}$ and $833.87 \mathrm{gC} / \mathrm{m}^{2}$, respectively, with the former closer to the MOD17A3 NPP value, while the latter value was significantly higher. Although the CASA model was used in this paper and in both studies previously discussed, the parameter acquisition methods used in each implementation of the CASA model were very different, which manifested in the acquisition of solar radiation, potential evapotranspiration and actual evapotranspiration, and the absorption components of the photosynthetically active radiation of the vegetation. The data used for comparison with the calculated NPP results were MOD17A3 NPP data, which were also simulated by a model. If the measured NPP data could be obtained from different regions, altitudes, and vegetation types, the results would be more applicable for solving practical management problems. Through the comparison of applied NPP models in the Qinling Mountains, the CASA model was found to have more advantages than the Comprehensive model.
(2) The climate and vegetation in the Qinling Mountains have obvious vertical zonal characteristics. The warming climate has influenced spatial heterogeneity in the observed changes in vegetation in the region [39]. From 1982 to 2015, the vegetation NPP in the Qinling Mountains showed an increasing trend over a large spatial area at the inter-annual and spring seasonal scales and a significant positive correlation with precipitation. The area ratios of other significant correlations were relatively low. These results were quite different from a previous NDVI analysis of vegetation changes in the Qinling Mountains [40], which showed that NPP was less sensitive to climate change than NDVI. It should also be noted that the reduced NPP area in the Qinling Mountains was mainly concentrated in areas with intense human activities, such as the Shangluo, Ankang, and Hanzhong Basins. Human activity was the main reason for decreasing NPP in the Qinling Mountains [41]. The increase in NPP caused by climate change, especially the warming and humidification, was not obvious and reflected the complexity and spatial heterogeneity of the mountainous climate and vegetation systems.

(3) Only two climatic factors were selected for analysis in the paper, while extreme climatic factors such as the palmer drought severity index (PDSI), standardized precipitation index (SPI), and standardized precipitation evapotranspiration index (SPEI), were not selected. This research lacked analysis on the relationship between extreme climatic events (extreme drought or humidity) and NPP in the Qinling Mountains. Studies have previously shown that the impact of extreme climate events on NPP was relatively large [11, 16, 19]. Therefore, the effects of extreme drought and extreme humidity on the vegetation in the Qinling Mountains deserve further research. 


\section{Conclusions}

We estimated NPP in the Qinling Mountains from 1982 to 2015 using GIMMS NDVI data, meteorological data, DEM data, vegetation type, and the Comprehensive and CASA models. Moreover, the NPP calculated by the CASA model was used to analyze the spatial and temporal changes in NPP and their relationship with air temperature and precipitation. Results showed that the CASA model had obvious advantages over a traditional climate statistical model such as the Comprehensive model in simulating NPP values. When vegetation was not considered, simulated NPP calculated using the CASA model and GIMMS NDVI were the most accurate. From 1982 to 2015, the spatial and temporal changes in vegetation NPP generally showed an increasing trend with obvious spatial heterogeneity. The NPP area that showed a significant increasing trend at inter-annual and spring seasonal scales was higher than that showing a significant downward trend in winter. As the region warmed and humidified during 1982 to 2015, the effect of increased precipitation on vegetation NPP was higher than that of the increased air temperature. The increased NPP area at interannual and spring seasonal scales caused by increased precipitation was higher than that caused by an increase in air temperature in spring and autumn. Under the background of a warmer and more humid climate in the Qinling Mountains, the relationship between NPP change and climate change was not obvious, which may reflect the complexity and spatial heterogeneity of a mountainous climate and vegetation system.

\section{Acknowledgements}

This work was supported by the National Natural Science Foundation of China (41501571, 41807503), the Scientific Research Program Funded by the Shaanxi Provincial Education Department (18JK0524), and 2018ZDXM-GY-027.

\section{Conflict of Interest}

The authors declare no conflict of interest.

\section{References}

1. WHEELER T., VON BRAUN J. Climate change impacts on global food security. Science, 341 (6145), 508, 2013.

2. REVESZ R.L., HOWARD P.H., ARROW K., GOULDER L.H., KOPP R.E., LIVERMORE M.A., OPPENHEIMER M., STERNER T. Global warming: Improve economic models of climate change. Nature, 508 (7495), 173, 2014.

3. EXBRAYAT J.F., BLOOM A.A., FALLON P., ITO A., SMALLMAN T.L., WILLIAMS M. Reliability ensemble averaging of $21^{\text {st }}$ century projections of terrestrial net primary productivity reduces global and regional uncertainties. Earth System Dynamics, 9, 153, 2018.

4. JACQUELINE G.F., ANTOINE G., NIKLAUS E.Z. Tree line shifts in the Swiss Alps: climate change or land abandonment? Journal of Vegetation Science, 18, 571, 2007.

5. HU..ANG..YUE C., SHEN H.H. Global warming, humaninduced carbon emission, and their uncertainties. Science China Earth Sciences, 54, 1458, 2011.

6. ANG X.L., ZHAO X., BAI Y.F., TANG Z.Y., WANG W.T., ZHAO Y.C., WAN H.W., XIE Z.Q., SHI X.Z., WU B.F., WANG G.X., YAN J.H., MA K.P., DU S., LI S.G., HAN S.J., MA Y.X., HU H.F., HE N.P., YANG Y.H., HAN W.X., HE H.L., YU G.R., FANG J.Y., ZHOU G.Y. Carbon pools in China's terrestrial ecosystems: new estimates based on an intensive field survey. PNAS, 115 (16), 4021, 2018.

7. ZHAO F.B., WU Y.P., SIVAKUMAR B., LONG A.H., QIU L.J., CHEN J., WANG L.J., LIU S.G., HU H.C. Climatic and hydrologic controls on net primary production in a semiarid loess watershed. Journal of hydrology, 568, 803, 2019.

8. ZHANG X.L., XIAO W.H., WANG Y.C., WANG Y., WANG H.J., WANG Y.X., ZHU L.S., YANG R.X. Spatial-temporal changes in NPP and its relationship with climate factors based on sensitivity analysis in the Shiyang River Basin. Journal of Earth System Science, 129 (1), 24, 2020.

9. WEN Y.Y., LIU X.P., BAI Y., SUN Y., YANG J., LIN K., PEI F.S., YAN Y.C. Determining the impacts of climate change and urban expansion on terrestrial net primary production in China. Journal of environmental management, 240, 75, 2019.

10. SIMIONI G., MARIE G., DAVI H., MARTIN-STPAUL N., HUC R. Natural forest dynamics have more influence than climate change on the net ecosystem production of a mixed Mediterranean forest. Ecological Modelling, 416, 108921, 2020.

11. NEMANI R.R., KELLING C.D., HASHIMOTO H., JOLLY W.M., PIPER S.C., TUCKER C.J., MYNENI R.B., RUUNING S.W. Climate-driven increases in global terrestrial net primary production from 1982 to 1999. Science, 300 (5625), 1560, 2003.

12. ZHAO M.S., RUNNING S.W. Drought-induced reduction in global terrestrial net primary production from 2000 to 2009. Science, 329 (5994), 940, 2010.

13. ZHAO M.S., RUNNING S.W. Response to comments on "Drought-induced reduction in global terrestrial net primary production from 2000 to 2009". Science, 333 (6046), 1093, 2011.

14. ZHU L.K., SOUTHWORTH J. Disentangling the relationship between net primary production and precipitation in southern Africa Savannas using satellite observations from 1982 to 2010. Remote Sensing, 5, 3803, 2013.

15. LI S.S., LV S.H., LIU Y.P., GAO Y.H., AO Y.H. Variations and trends of terrestrial NPP and its relation to climate change in the 10 CMIP5 models. Journal of Earth Science, 124 (2), 395, 2015.

16. LI T.H., WANG Z.N. Estimation of monthly net primary productivity and its variation characteristics in Shenzhen based on CASA model, GIS and RS. Journal of Basic Science and Engineering, 20 (Supplement), 126, 2012 [In Chinese with English abstract].

17. ZHAO L., XU C.X., LIU X.Y., LI H.Q., JIANG H.H., LIN A.W. Impacts of meteorological drought on net primary productivity of forest in Hubei Province. Resources and 
Environment in the Yangtze Basin, 23 (11), 1595, 2014 [In Chinese with English abstract].

18. PEI F.S., LI X., LIU X.P., LAO C.H. Assessing the impacts of droughts on net primary productivity in China. Joural of Environmental Management, 114, 362, 2013.

19. SUN B.F., ZHAO H., WANG X.K. Effect of drought on net primary productivity: roles of temperature, drought intensity, and duration. Chinese Geographical Science, 26 (2), 270, 2016

20. LI L., HE X.J., HU L.L., LI J.S. Simulation of the carbon cycle of Larix chinensis forest during 1958 and 2008 at Taibai Mountain China. Acta Ecologica Sinica, 33 (9), 2845, 2013 [In Chinese with English abstract].

21. JIANG C., WANG, F., Mu X.M., LI R. Effects of climate changes on net primary productivity (NPP) of vegetation in Han River Basin. Journal of Northwest Forestry University, 28 (1), 51, 2013 [In Chinese with English abstract].

22. JIANG C., WANG W.L., CHEN A.F., LI J.G., WANG F., MU X.M., LI R. Effect of climate change on net primary productivity of vegetation in the Weihe River Basin. Journal of Desert Research, 33 (3), 952, 2013 [In Chinese with English abstract].

23. YUANG B., BAI H.Y., ZHANG J., MA X.P. Vegetation net primary productivity in Qinling Mountain and its response to climate change. Bulletin of Botanical Research, 33 (2), 225, 2013 [In Chinese with English abstract].

24. WANG J., ZHUO J., HE H.J., DONG J.F. Changes of vegetation net productivity and its driving factors from 2000 to 2013 in Qinling Mountainous area. Journal of Northwest Forestry University, 31 (5), 238, 2016 [In Chinese with English abstract].

25. LIETH H. Primary production: terrestrial ecosystems. Human Ecology, 1 (4), 303, 1973.

26. UCHIJIMA Z., SEINO H. Agroclimatic evaluation of net primary productivity of natural vegetations. Journal of Agricultural Meteorology, 40 (4), 343, 1985.

27. ZHU Z. H. Estimation model of net primary productivity of natural vegetation. Chinese Science Bulletin, 38 (15), $1422,1993$.

28. ZHOU G.S., ZHANG X.S. A natural vegetation NPP model. Acta Phytoecologica Sinica, 19 (3), 193, 1995 [In Chinese with English abstract].

29. POTTER C.S., RANDERSON J.T., FIELD C.B., MATSON P.A., VITOUSEK P.M., MOONEY H.A., KLOOSTER S.A. Terrestrial ecosystem production: a process model based on global satellite and surface data. Global Biogeochemical Cycles, 7 (4), 811, 1993.

30. YIN Y.H., WU S.H., ZHENG D., YANG Q. Radiation calibration of FAO056 Penman-Monteith model to estimate reference crop evapotranspiration in China. Agricultural Water Management, 95, 77, 2008.
31. LIU G.H., HUANG C., LI Y.F., ZHANG H.L. Study on vegetation pattern and net primary productivity simulation in Lancangjiang River Basin. Science Press, Beijing, pp. 65, 2015 [In Chinese].

32. TAKAHASHI, KOICHIRO. The formula for calculating evapotranspiration from monthly mean temperature and monthly precipitation. Weather, 26 (1), 29, 1979 [In Chinese with English abstract].

33. ZHU W.Q., CHEN Y.H., PAN Y.Z., LI J. Estimation of light utilization efficiency of vegetation in China based on GIS and RS. Geomatics and Information Science of Wuhan University, 29 (8), 694, 2004 [In Chinese with English abstract].

34. GULBEYAZ O., BOND-LAMBERTY B., AKYUREK Z., WEST T.O. A new approach to evaluate the MODIS annual NPP product (MOD17A3) using forest field data from Turkey. International Journal of Remote Sensing, 39 (8), 2560, 2018

35. REN H., SHANG Y., ZHANG S. Measuring the spatiotemporal variations of vegetation net primary productivity in Inner Mongolia using spatial autocorrelation. Ecological Indicators, 112, 106108, 2020.

36. WANG T., YANG M.H. Land use and land cover change in China's Loess Plateau: the impacts of climate change, urban expansion and grain for green project implementation. Applied Ecology and Environmental Research, 16 (4), 4145, 2018.

37. JIANG C., WANG F., MU X.M., LI R. Effects of temperature and precipitation variation on vegetation net primary productivity in the northern and southern regions of the Qinling Mountain from 1960 to 2011. Acta Biotanica Boreali-Occidentalia Sinica, 32 (9), 1888, 2012 [In Chinese with English abstract].

38. ZHANG S.H., DING X.S. Remote-sensing estimation of NPP and its spatial-temporal change characteristics in Qinling Mountain region. Acta Agriculture Jiangxi, 29 (8), 124, 2017 [In Chinese with English abstract].

39. JIANG C., MU X. M., WANG F., ZHAO G.J. Analysis of extreme temperature events in the Qinling Mountains and surrounding area during 1960-2012. Quaternary International, 392, 155, 2016.

40. WANG T., BAI H.Y. Variation of vegetation NDVI in response to climate changes and human activities in Qinling Mountains. Mountain Research, 35 (6), 778, 2017. (In Chinese with English abstract)

41. LIU X.F., ZHU X.F., PAN Y.Z., LI S.S., MA Y.Q., NIE J. Vegetation dynamics in Qinling-Daba Mountains in relation to climate factors between 2000 and 2014. Journal of Geographical Science, 26 (1), 45, 2016. 